ENSAIO

Recebido em: 02/02/2017

Aceito em: 01/07/2017

\title{
A Classificação de Livros de William Torrey Harris: influências de Bacon e Hegel nas classificações de biblioteca
}

\author{
The book classification of William Torrey Harris: Influences of Bacon \\ and Hegel in library classification
}

Resumo: Os estudos das classificações de biblioteca comumente dialogam com a contextualização de abordagem histórica e com as ideias classificatórias próprias da Filosofia. No século XIX, o filósofo e educador norteamericano William Torrey Harris desenvolveu uma classificação de livros para a Escola Pública de St. Louis, que trouxe em seu cerne influências tanto de Francis Bacon como de Georg Wilhelm Friedrich Hegel. 0 objetivo do presente ensaio é analisar a classificação de Harris, refletindo acerca de suas bases teórica e filosófica. Para tanto, adotou-se um olhar crítico-descritivo para a realização da análise. Como resultado, foi possível apresentar algumas influências de Bacon e de Hegel na classificação Harris.

Palavras-Chave: Classificação de livros. Classificação de biblioteca. William Torrey Harris. Francis Bacon. Hegel.

\begin{abstract}
The studies of library classification generally interact with the historical contextualization approach and with the classification ideas typical of Philosophy. In the 19th century, the North-American philosopher and educator William Torrey Harris developed a book classification at the St. Louis Public School, based on Francis Bacon and Georg Wilhelm Friedrich Hegel. The objective of this essay is to analyze Harris's classification, reflecting upon his theoretical and philosophical backgrounds. To achieve such objective, this essay adopts a critical-descriptive approach for analysis. Results show some influences of Bacon and Hegel in Harris's classification.
\end{abstract}

Keywords: Book classification. Library classification. William Torrey Harris. Francis Bacon. Hegel.
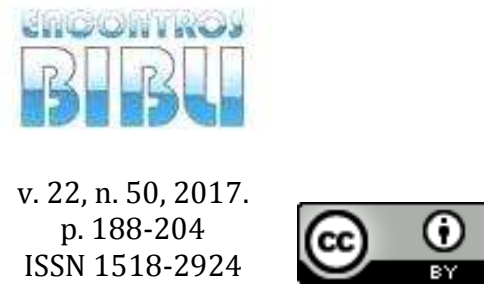

Esta obra está licenciada sob uma Licença Creative Commons 


\section{INTRODUÇÃo}

Every scheme of classification rests upon some philosophical system as its basis.

W. T. Harris

A história das classificações do conhecimento, no mundo ocidental, é tradicionalmente abordada pela literatura a partir de pensadores da Grécia Antiga, que concebiam o mundo como um todo harmônico, onde os saberes estariam relacionados de tal forma que comporiam juntos um conhecimento universal. Neste período histórico, propagava-se a ideia de que a classificação do conhecimento se tratava de um exercício mental que dava lugar às coisas e às ideias que se tinham das coisas existentes. Para tanto, fazia-se necessário agrupar os saberes tanto em uma perspectiva mais abrangente, como na divisão das disciplinas realizada por Platão (Física, Ética e Lógica) e por Aristóteles (disciplinas teóricas, práticas e poéticas), quanto em uma perspectiva mais individualizante, como nas categorias fundamentais de Aristóteles (categorização do que pode se saber a respeito de um ente) e na árvore de Porfírio (consolidação da divisão dicotômica). Embora fossem deferentes as propostas de cada filósofo, por exemplo, enquanto Platão se ocupava com a organização do mundo abstrato das ideias, Aristóteles pretendia descrever o mundo sensível das coisas concretas, no legado de ambos os pensadores estão visíveis alguns elementos pioneiros na lógica classificatória (Sales 2016).

Adentrando ao período Medieval, verifica-se que a classificação do conhecimento era principalmente definida pelos currículos das universidades europeias, que exerceriam forte influência na classificação do conhecimento não somente da Idade Média, mas também nas classificações desenvolvidas na Idade Moderna. Segundo Burke (2003), os currículos medievais estavam estruturados em três grandes grupos de disciplinas: trivium, quadrivium e estudos superiores. 0 trivium era composto pelas chamadas ciências da linguagem (Gramática, Dialética e Retórica) e o quadrivium era constituído pelas denominadas ciências dos números (Geometria, Aritmética, Astronomia e Música). Já os estudos superiores contemplavam as áreas de Teologia, Direito e Medicina (Burke, 2003). Somente na Idade Moderna, principalmente a partir do século XVII, é que disciplinas relacionadas às humanidades ganhariam espaço nos currículos europeus.

Do século XV ao século XVIII pensadores como Poliziano (1454-1494), Nizolio (1498- 1556), Huarte (1535-1592), Bacon (1561- 1626) e Hegel (17701831) empreenderam esforços para organizar os saberes de uma maneira fortemente influenciada pelo princípio de divisão tripartitivo de Aristóteles. Pode-se citar, ainda, Descartes (1596-1650), Hobbes (1599-1679), Locke (1632-1704), Leibnitz (1646-1715), Benthan (1748-1832), Ampère (1775-1836), Comte (17981857), Stuart Mill (1806-1873), Spencer (1820-1903) e Wundt (1832-1920), como autores de classificações que propunham uma ordem lógica para os conhecimentos, estabelecendo, assim, diferentes perspectivas classificatórias.

Mas foi a partir da segunda metade do século XIX que a classificação deixou de ser puramente científica ou filosófica e começou a desempenhar seu caráter mais aplicado de organização da informação, ou seja, dar ordem também aos conhecimentos materializados, servindo de base para a organização de acervos de bibliotecas e a consequente localização de livros. Nos Estados Unidos, William Torrey Harris, Melvil Dewey e Charles Ammi Cutter, por exemplo, começaram a investir esforços na organização sistemática dos assuntos existentes nos livros das bibliotecas. Concomitantemente, na Europa, Paul Otelt e Henri La Fontaine investiram na organização de informações bibliográficas de documentos das mais variadas naturezas (Sales, 2016). 
Em 1870, o filósofo e educador norteamericano William Torrey Harris (1835-1909), responsável então pela rede de bibliotecas das escolas públicas de St. Louis (EUA), elaborou uma classificação de livros que, com base na filosofia hegeliana, invertia a lógica da classificação filosófica definida por Francis Bacon em 1605. A classificação definida por Harris seria fundamental para a concepção do primeiro esquema de classificação bibliográfica de alcance reconhecidamente internacional, a Classificação Decimal de Dewey (BARBOSA, 1969; FOSKETT, 1973; PIEDADE, 1983; WIEGAND, 1996; OLSON, 2011).

Embora Harris seja significativamente reconhecido nas áreas da Filosofia e da Educação, tanto nos Estados Unidos como em países estrangeiros (LEIDECKER, 1946), na Biblioteconomia e nos estudos de organização do conhecimento o nome de Harris tem figurado apenas como o criador da classificação que influenciou a classificação de Mevil Dewey. E pouco ou quase nenhum estudo tem se ocupado em analisar a classificação de Harris propriamente dita.

A reflexão teórica comunicada neste ensaio teve como objetivo analisar a classificação publicada por Harris em 1870, destacando não somente seu papel na história das classificações de biblioteca, mas, principalmente, refletindo acerca de suas bases teórica e filosófica. Nesse sentido, abordou-se a contribuição de Harris como uma ligação entre a Filosofia e a Biblioteconomia. Assim, cabe ressaltar que a análise da classificação foi realizada com base no artigo Book Classification publicado por Harris em 1870, talvez, o único texto em que Harris volta-se explicitamente à atividade biblioteconômica. Tal análise, que apresentou um caráter crítico-descritivo, foi respaldada em escritos de estudiosos das classificações de biblioteca, estudiosos da filosofia e da história da filosofia, além de biógrafos de classificacionistas.

\section{CLASSIFICAÇÕES DE BIBLIOTECA NA AMÉRICA: UMA CONTEXTUALIZAÇÃo HISTÓRICA}

A história das classificações de biblioteca $^{1}$, sobretudo no continente americano, encontrou no século XIX um espaço de desenvolvimento que merece atenção especial. Afirmar que o século XIX foi o ponto de partida das classificações de bibliotecas na América do Norte seria ignorar a classificação da Bibliotheca Parochialis, do Reverendo Thomas Bray, publicada em 1697, a classificação do Harvard College (de 1723), a classificação do Yale College (de 1743) e a classificação da Library Company of Philadelphia (de 1789) (LA MONTAGNE, 1961).

Embora algumas classificações já tivessem sido desenvolvidas e utilizadas em bibliotecas dos Estados Unidos nos séculos XVII e XVIII, fato é que somente no século XIX as classificações de bibliotecas ganharam espaço e notoriedade a ponto de conquistar uma dinâmica de trabalho e uma interlocução mais sólidas. Em período anterior ao século XIX, como afirma La Montagne (1961), não havia canais formais para a troca de ideias e os bibliotecários trabalhavam as questões das classificações de maneira isolada. Somente após a segunda metade do século XIX este cenário começou a se modificar nos Estados Unidos. A classificação adotada na Encyclopaedia Metropolitana utilizada no contexto da Tennessee State Library, em 1855, a classificação desenvolvida por Edward William Johnston na St. Loius Mercantile Library, em 1858, e o catálogo analítico da Library of the U.S. Naval Academy, de 1860, são exemplos de instrumentos classificatórios surgidos nos Estados Unidos naquele período.

\footnotetext{
10 termo classificações de biblioteca será aqui empregado conforme adotado por autores como Leidecker (1946), La Montagne (1961) e Weigand $(1996 ; 1998)$. Por vezes, a literatura prefere o termo classificação bibliográfica. Harris (1870) adotou o termo book Classification.
} 
La Montagne (1961), que dividiu a história das classificações das bibliotecas americanas em pré-história e história, afirma que a década de 1870 foi um divisor de águas para os estudos de classificações de biblioteca no país, atribuindo a esta década o início da história das classificações das bibliotecas americanas. Segundo Schneider (1934),

The work of developing bibliographical classification schemes began later in the United States than in other countries, but once begun it was carried on with great zeal. Interest in classification first arose in the United States in the seventies (SCHNEIDER, 1934, p. 210).

Foi justamente na década de 1870 que o filósofo e educador norte-americano William Torrey Harris surgiu como figura central no universo das classificações de biblioteca, não somente para os Estados Unidos, mas para todo o mundo ocidental, uma vez que a base de sua classificação repercutiria diretamente nas classificações bibliográficas de maior influência no âmbito internacional, a Classificação Decimal de Dewey (CDD) e a Classificação Decimal Universal (CDU). Conforme afirmam Comaromi (1976), Weigand (1996; 1998) e Olson (2011), as classes principais do sistema decimal de Dewey foram definidas com base na estrutura da classificação da Biblioteca da Escola Pública de St. Loius, elaborada por Harris em 1870, assim como as subclasses e as seções do sistema de Dewey foram baseadas nas estruturas dos cursos e textos dos professores do Amherst College, entre os anos de 1870 e 1875. Weigand $(1996 ; 1998)$ publicou trechos de uma carta datada de 9 de maio de 1873 onde Dewey escreve à Harris pedindo mais informações a respeito do arranjo da classificação da Biblioteca de St. Louis.

Neste período, o ambiente acadêmico e profissional no qual Harris estava inserido se encontrava fortemente influenciado pelo idealismo hegeliano, influência que refletiria também entre os pensadores do Amherst College, onde se encontrava Melvil Dewey (WEIGAND, 1996; OLSON, 2011). Segundo o biógrafo de Harris, Leidecker (1946), no ano de 1873 Harris e Dewey estavam bastante próximos, unidos não somente pelas classificações de biblioteca, mas também pelo interesse na reforma ortográfica da língua inglesa nos EUA.

Se no século XIX nos Estados Unidos a classificação de Harris vinha repercutindo na classificação de Dewey, na Europa, no início do século XX, a Classificação Decimal Universal, elaborada com base na quinta edição da CDD, já alcançava ampla aceitação no universo científico europeu, e trazia em sua estrutura a herança lógica da classificação de Harris. Desse modo, observa-se que a classificação desenvolvida por Harris, exerceu grande influência nas classificações americanas e europeias, imprimindo sua presença de maneira especial na dimensão histórica do discurso científico relativo às classificações de biblioteca, tanto na América quanto na Europa.

\section{WILLIAM TORREY HARRIS}

Nascido em North Killingly (Putnam), Connecticut, em 10 de setembro de 1835, William Torrey Haris desde muito jovem se ocupava com as classificações de bibliotecas. Em 1858 inventou uma classificação para a sua própria coleção, que contava com 367 itens bibliográficos (LEIDECKER, 1946). Anos antes, em 1854 ingressou em Yale, mas logo abandonou o curso alegando que o college pouco tinha a lhe ensinar (LA MONTAGNE, 1961). Juntou-se ao seu colega de classe, Robert Seney Moore, com quem compartilhou grande interesse em taquigrafia. Segundo La Montagnge (1961), em 1858 Harris foi nomeado professor no Franklin Grammar School, em St. Louis, e permaneceu no sistema público de St. Loius como professor, diretor, superintendente assistente e superintendente, respectivamente, até 1880. 
Dentre os antigos interesses de Harris estavam ainda a parapsicologia, a fenomenologia e a hidropatia.

Voltando-se aos trabalhos de Theodore Parker, Harris foi despertado por um grande e prolongado interesse pela literatura e pela filosofia alemã e teve a oportunidade de encontrar um estudante de Hegel e Goethe, Henry Conrad Brokmeyer, responsável pelo início da formação da base hegeliana de Harris (LA MONTAGNE, 1961). Harris ajudou a fundar, em 1866, o St. Louis School of Philosophy, onde criou, anos depois, o Journal of Speculative Philosophy, que contava com a colaboração de Charles S. Peirce, Josiah Royce, John Dewey e William James. Em 1880 retornou ao leste americano, agora no Concord School of Philosophy, Massachusetts, e aprofundou seus estudos e discussões sobre a dialética hegeliana, nunca se distanciando de sua característica de incentivador e reformista da educação pública.

Em 1889, Harris foi nomeado, pelo então presidente americano Benjamim Harrison, Comissionário da Educação dos Estados Unidos, posição que ocupou até 1906. Segundo La Montagne (1961), a bibliografia escrita por Harris soma 479 títulos, predominantemente composta por textos filosóficos e educacionais. Harris faleceu em Providence, Rhonde Island, em 5 de novembro de 1909.

Os arquivos pessoais de Harris estão na Divisão de Manuscritos da Library of Congress, Washington, D.C., e toda bibliografia escrita por Harris ou escrita sobre ele se encontra nas coleções da Library of Congress (LOC).

Foi no âmbito de um curso realizado para as escolas de St. Louis que Harris começou realmente a se interessar por classificações de biblioteca. Segundo La Montagne (1961), Harris alegava que as bibliotecas eram fundamentais para a educação moderna e que bons catálogos eram imprescindíveis para que as bibliotecas fossem de fato eficientes. Os produtos disponíveis na época, que se restringiam aos índices de autores, eram insuficientes, e Harris reclamava por um índice de assuntos que conduzisse o leitor diretamente aos temas dos livros.

Já foi amplamente difundido pela literatura o fato de que Harris desenvolveu seu sistema de classificação invertendo a lógica baconiana baseada nas faculdades mentais. Francis Bacon havia definido suas classes de assuntos em História, Poesia e Filosofia. Harris as inverteu em seu esquema classificatório, dando a seguinte configuração: Ciência/Filosofia, Belas Artes e História. Esta informação, compartilhada por Leidecker (1946), Foskett (1973), Olson (2011), entre outros, outorgam Harris como personalidade importante na história das classificações de biblioteca dos Estados Unidos. Outros, como Weigand (1996), entendiam que a inversão das classes baconianas já havia sido realizada pelo próprio Hegel em sua dialética idealista. Já La Montagne (1961) defendia a ideia de que quem adotou pela primeira vez a inversão das classes de Bacon foi Edward William Johnston, no âmbito do College of South Carolina, em 1836. Mas, a despeito das mencionadas divergências, fato é que a literatura converge ao afirmar que a classificação de Harris teve uma importância singular na história das classificações de biblioteca, pois além de exercer forte influência nas classificações universais subsequentes, a classificação de Harris trouxe ao universo das classificações de biblioteca um diálogo mais intenso com as bases das classificações filosóficas, notadamente, no caso de Harris, com o pensamento de Bacon e de Hegel. Em outras palavras, Harris uniu sua base filosófica com as preocupações práticas do universo classificatório das bibliotecas.

Com efeito, o sistema de classificação definido por Harris foi adotado minuciosamente como base para o catálogo da Biblioteca da Escola Pública de St. Louis. A ideia de Harris era a concepção de um catálogo que contemplasse as necessidades de busca de informações não somente de bibliotecários, mas também de estudantes de Filosofia que desejassem um olhar abrangente sobre a totalidade da inteligência humana materializada nos livros (HARRIS, 1870). 


\section{UM OLHAR CRÍTICO-DESCRITIVO NA CLASSIFICAÇÃO DE HARRIS}

Para analisar a classificação de Harris é necessário referenciar tanto o pensamento classificatório de Bacon quanto a lógica idealista de Hegel. Assim, optou-se por uma análise no artigo Book Classification - publicado originalmente por Harris em 1870 no de The Journal of Speculative Philosophy - subsidiada por obras de estudiosos das classificações e da Filosofia. Desse modo, a análise foi em parte descritiva, onde foram apresentados aspectos fundamentais da classificação publicada no artigo Book Classification, e, em parte crítica, onde foram relacionadas as perspectivas classificatórias de Bacon e Hegel com a classificação de Harris.

\subsection{0 artigo de 1870: um olhar descritivo}

Harris, envolvido com a Biblioteca da Escola Pública de St. Louis, demonstrou sua preocupação com o trabalho dos bibliotecários ao iniciar seu artigo destacando a dificuldade que estes profissionais encontravam ao lidar com a classificação de coleções de livros e com a elaboração de catálogos de bibliotecas.

Whoever has had occasion to consult the classified catalogues of Libraries in this country, or in Europe, has no doubt experiencied the difficult met with in determining what classes he shall search in order to find books treating on the topics of his investigation. The difficult experienced by the investigator is still more troublesome to the corpas of librarians. To determine the exact class to which the book belongs, to place it where it can be found again at once when inquired for, to open to the scholar seeking information the entire resources of the library on a special theme, - these are constant duties of the librarian that imply a good system of classification (HARRIS, 1870, p. 114).

Entendendo que todo sistema de classificação deveria ser suportado por uma lógica filosófica, Harris iniciou sua argumentação classificatória reportando-se ao pensamento de Francis Bacon. Para Harris (1870), embora Bacon não tivesse por objetivo a classificação de livros, ele acabou por apresentar um princípio de desenvolvimento do conhecimento humano (apresentado na obra De Augmentis Scientiarum, Livro II, cap. I) que serviria de distinção fundamental para classificar o conhecimento. Este princípio era baseado nas distintas faculdades mentais do homem que, segundo Bacon, consistiam na Memória, na Imaginação e na Razão. A partir da referida distinção, Bacon definiu três grandes áreas do saber: a História (que corresponderia à Memória), a Poesia (que se referia à Imaginação) e a Filosofia (relativa à Razão).

Valendo-se desta ideia formativa do conhecimento para a elaboração de uma classificação de livros, Harris destacou algumas falhas no fazer classificatório vigente na época. Chamou a atenção para o fato de que o conteúdo (sobre o que o livro trata) não seria uma base sólida para fundamentar tal classificação, afinal, uma classe de livros poderia tratar de diferentes fases do conteúdo de uma só vez. Na concepção de Harris (1870), Nature and Mind, por exemplo, não existem isoladamente, mas sim em algum grau de síntese. Desse modo, um livro que tratasse de ambos os assuntos seria de difícil acomodação em um sistema de classificação. Percebe-se, aqui, uma forte influência hegeliana no pensamento de Harris, uma vez que para Hegel o conhecimento absoluto só era possível por meio de um processo de mutação (um devir), ou seja, por meio de uma dialética idealista formada por uma tese, uma antítese e uma síntese. Se o idealismo hegeliano considerava que o conhecimento estava na compreensão do "movimento" de diferentes fases que compõe o processo de "conhecer", naturalmente que Harris se oporia a ideia de 
classificar assuntos de maneira isolada, como se cada objeto de estudo tivesse, por si só, significado suficiente. Talvez isso explique porque Harris tenha se inspirado em Bacon como ponto de partida para sua classificação, pois Bacon defendia uma classificação baseada na "formação" do conhecimento por meio das faculdades mentais, o que pressupunha, ao menos, que para se organizar (classificar) o conhecimento era necessário estar atento ao processo formador do mesmo. entender que

Para Harris (1870), o erro principal dos classificacionistas estava em

the classifications of science would answer equally well for the classification of de books of a library; and whereas science has for its domain all existence, and to some degree can be classified by its object-matter, they have sought to divide books on the same plan (HARRIS, 1870, p. 115).

Após apresentar alguns exemplos de classificações que incorreram neste tipo de erro, especialmente entre os séculos XVIII e XIX, Harris retoma a discussão em torno da classificação com base na distinção preconizada por Bacon, afirmando ser possível emprega-la para classificações de biblioteca. Para Harris (1870), Bacon não tinha a pretensão de utilizar na prática sua distinção classificatória, por isso não chegou a desenvolver uma forma apropriada para aplica-la. Muito provavelmente, segundo Harris (1870), isso nem seria possível, pois no tempo de Bacon as ciências ainda não tinham sido desdobradas a ponto de alcançar as formas que depois assumiriam. Assim, pensando em contornos mais históricos, Bacon decidiu encabeçar seu esquema com a divisão da "História", que ocuparia um espaço de destaque em sua classificação. Segundo Olson (2011), a influência renascentista no pensamento de Bacon, advinda de Aristóteles e da classificação medieval do conhecimento em função da pedagogia, foi complementada por um método dialético. Bacon "considerava que a Memória era o repositório básico das experiências, que, quando comparado e contrastado via Imaginação, podia ser processado via Razão e transformado em conhecimento" (OLSON, 2011, p.7). Ao unir a explicação de Harris (1870) a respeito da conjuntura em que vivia Bacon e a dialética baconiana apresentada por Olson (2011), é possível inferir que tal conjuntura - predominância das formas históricas e/ou insuficiência das formas científicas - levou Bacon à construção de sua dialética, onde a história alcançava espaço de primazia. Em outras palavras, tratava-se de uma classificação possível a um filósofo britânico dos séculos XVI e XVII.

Harris (1870) prossegue sua explicação afirmando ser este o motivo que levou Bacon a submeter a Filosofia como a terceira divisão de sua classificação, subtraindo aquilo que, no século XIX, seriam as formas mais óbvias da Filosofia - as Ciências.

Toda classificação, por mais universalista que se pretenda, não consegue escapar dos limites de sua época. No caso de Bacon, não somente os incipientes desdobramentos científicos flagravam a forma de pensar do século XVII, mas também os desdobramentos artísticos. Conforme colocou Harris (1870), o desenvolvimento ainda precário da ficção em prosa levava obras clássicas da literatura, tais como os romances de Lúcio Apuleio e as novelas de Giovanni Boccaccio, a serem alocadas na segunda divisão da classificação de Bacon, todas submetidas à denominação de Poesia.

Harris (1870) afirma que em seu tempo, diferentemente do tempo de Bacon, o reino da "compreensão" e da "razão" era chamado de Ciência, e o reino da "fantasia" e da "imaginação produtiva" era chamada de Arte ou Estética. A ligação etimológica da palavra Poesia - dar determinação a algo; moldar; criar para dada determinação - concede um significado criativo adaptado para nomear as obras de Imaginação Produtiva. 
Após explicitar o contexto em que Bacon definiu sua classificação, Harris (1870) apresenta um esboço do esquema de Bacon.

Tabela 1: Classes do esquema de Bacon.

HISTORY
A Natural History
B Civil History
C Appendix to History
POETRY
A Narratice or Heroic
B Dramatic
C Allegorical. Fables, Mithologies
PHILOSOPHY
A Theology or Divine Philosophy
B Natural Philosophy
C Philosophy of Man

Fonte: Harris (1870)

Conforme dito anteriormente, Harris ressalta que a classificação de Bacon, embora não tenha sido criada com o propósito de organizar livros de bibliotecas, apresentava um princípio de divisão que deveria ser aproveitado e mantido para tal fim. Segundo Harris (1870), as subdivisões e seções menores do sistema de Bacon eram guiadas pelo conteúdo, ao passo que as classes maiores eram orientadas pela forma. Por exemplo, a classe geral História (forma de abordar o conhecimento) era dividia pelas classes História Natural, História Civil e Apêndice para História (conteúdos da História). De igual maneira, a classe geral Filosofia (forma de abordar o conhecimento) era dividida pelas classes Teologia, Filosofia Natural e Filosofia do Homem (conteúdos da Filosofia).

Porém, se Harris concordava com a adoção de tais princípios de divisão, discordava, por sua vez, da ordem estabelecida por Bacon. Para Harris (1870), a Filosofia, que em seu tempo já assumia a forma de Ciência, "should come first on account of its furnishing the method and priciples" (p. 119). Para o autor, ao nos reportarmos ao universo dos livros, a ordem deveria ser:

I. Science gives the department of books in which conscious system prevails.

II. Art (Esthetics) gives the department of books in which "organic unity" or unconscious system prevails.

III. History gives the department in which the system is determined by accidental relations, such as time and place (HARRIS, 1870, p. 119).

A influência de Hegel no pensamento de Harris conduzia para uma ênfase mais marcante à Razão. A Lógica de Hegel, que considerava três categorias de existência - Ser, Essência e Ideia -, foi explanada por Harris na obra "Hegel's logic: a book on the genesis of the categories of the mind: A critical exposition", publicada em 1890. Na referida obra, conceituando o Ser como uma condição ilusória (aquilo que é imediatamente percebido), a Essência como uma condição de mediação (aquilo que está aparente não é uma realidade independente) e, a Ideia como uma categoria superior, Harris (1890) correlacionou a História com o Ser, como sendo observações ilusórias; as Artes com a Essência, como sendo mediações desiludidas e; a Ciência, a Filosofia e a Religião com a Ideia, como uma categoria que transcende tanto o ilusório quanto à mediação (OLSON, 2011). Observa-se em Harris, um esforço em lidar com a classificação de Bacon sob uma perspectiva hegeliana. Assim, ao contrário de Bacon, que entendia que primeiro o homem se lembra (memória), 
depois imagina (imaginação) e por último raciocina (razão), Harris preferiu dar em seu esquema primazia à Razão, entendendo que a ação racional deveria encabeçar a classificação do conhecimento, seguida pela imaginação e pela memória.

Harris defendia que o princípio da classificação não deveria ser simplesmente pautado nos objetos de estudo, como fizeram os classificadores das ciências, mas sim um princípio composto entre forma e conteúdo, que alcançasse, de algum modo, uma concretude e uma praticidade. Para tanto, Harris (1870) definiu algumas regras:

\section{Divisões principais:}

Iniciar sempre com os assuntos que estivessem mais próximos da realização do princípio característico da classe geral, ordenando-os sequencialmente com base nos assuntos que realizam tal princípio da maneira mais completa para a menos completa, marcando a transição para a classe seguinte. A classe seguinte devia ser ordenada com os assuntos mais intimamente ligados ao precedente, prosseguindo, posteriormente, para a transição à próxima classe. Por exemplo,

"Philosophy" is the highest type of Science, and hence begins the catalogue. Science ends with the useful Arts, which form a transition to division of Esthetic/Art, and this should commence with de Fine Arts, and be followed by Poetry. Geograph, as being of the most external character, precedes History (HARRIS, 1870, p. 120).

\section{Divisões finais:}

Os tratados gerais deveriam vir em primeiro lugar, incluindo os compêndios e as chamadas filosofias do assunto (que normalmente não passam de meros compêndios). Em seguida deveria vir o exemplo principal e mais relevante da classe superior, seguido por suas realizações menos importantes. Mas na Ciência este princípio é modificado pelo da ordem do desenvolvimento científico, onde primeiro se apresenta o resumo e depois os aspectos mais complexos e concretos. Como exemplo para as divisões finais, Harris (1870, p. 121) apresenta:

1st. Compends of History

2nd. Histories of Nations; this being the normal type of History

3rt. Biografy; this being History on a small scale.

\section{Apêndices:}

Coleções e miscelâneas deveriam ser localizadas no final da classe. Obras completas de um autor e coleções completas deveriam ser mantidas juntas respeitando o assunto abordado, sob um cabeçalho especial relativo ao assunto (HARRIS, 1870). Por exemplo, dicionários de belas artes seriam inseridos na classe Belas Artes, e não em Dicionários Gerais no Apêndice.

\section{Híbridos:}

Obras que não pertenciam exatamente a alguma seção ou que tratassem de assuntos heterogêneos que não convergiam com um cabeçalho mais geral, deveriam ser classificadas de acordo com o assunto predominante ou de acordo com a proposta principal do livro. Para esses casos, Harris (1870) sugeriu a elaboração de referências cruzadas no catálogo. 0 autor apresentou neste ponto uma clara preocupação em preservar o capital intelectual do autor da obra, e chegou a citar como exemplo: "Book on Architecture may fall under Mechanic Arts, or under Fine Arts, according to the point of view taken by the author in composing the work" (HARRIS, 1870, p. 121). 
Harris denominou estas regras de princípios norteadores (guiding principles), e toda sua classificação foi desenvolvida com base nesses princípios. Embora não seja possível ter certeza se primeiro Harris as estabeleceu para depois justificar os desdobramentos de sua classificação, respeita-se aqui a ordem apresentada no artigo de 1870, onde Harris primeiramente elencou tais princípios e depois explicitou sua lógica classificatória de assuntos. 0 autor colocou sua formação filosófica a serviço da resolução de problemas práticos das bibliotecas, uma vez que se observa um protagonismo compartilhado entre a abstração lógica dos assuntos e a característica formal dos livros, ou seja, o relacionamento científico dos assuntos e os aspectos formais do documento são tratados concomitantemente em seus princípios norteadores.

Explicitadas suas pretensões objetivas, Harris (1870) parte para a exposição lógica de seu esquema classificatório. Respeita-se, por ora, a sequência apresentada por Harris em seu artigo, que se limita às explicações referentes às classes gerais e às classes mais próximas das classes gerais.

a) Desdobramentos da Ciência (primeira classe geral / primeira divisão geral)2:

Para o autor, a Ciência estaria subdividida em Filosofia, Teologia, Ciências Sociais e Políticas, Ciências Naturais e Artes Úteis. Segundo Harris (1870) a Filosofia seria a responsável pela definição dos princípios mais gerais da ciência, responsável pelas formas e arquétipos que serviriam de fonte para estabelecer a sistematização das outras ciências, ou seja, a Filosofia forneceria o método sistemático. Para o filósofo americano, a Teologia seria a ciência do Absoluto que, assim como a Filosofia, caracterizar-se-ia como a ciência da Ciência.

$\mathrm{Na}$ concepção de Harris as chamadas Ciências Sociais e Políticas corresponderiam aos "treatises upon the institutions which relate man to his fellowmen in society and the state. His essential life as a spiritual being is conditioned upon his ascent above his merely natural, individual condition, by means of combination in the social organismo" (HARRIS, 1870, p. 122-3). 0 autor organiza esta classe em três partes: Ciência Política, composta por Jurisprudência e Política; Ciência Social, composta por Economia Política e Educação; e Filologia. Para Harris, a Jurisprudência dizia respeito ao organismo social como uma necessidade restritiva agindo externamente sobre o indivíduo. As ciências políticas e sociais seriam, assim, os meios pelos quais o indivíduo chegaria à compreensão da necessidade do organismo social e, com a Filologia tal restrição se tornaria interna e, portanto, livre (HARRIS, 1870).

A classe Ciências Naturais e Artes Úteis seria para Harris uma classe de transição entre as ciências e as artes. Para o classificacionista, as Ciências Naturais seriam as responsáveis pelo desdobramento das leis da Natureza, subdivididas em Matemática, Física e História Natural. A Matemática corresponderia à ciência das formas puras da Natureza, como o tempo e o espaço. A Física consistiria na Natureza abordada dinamicamente, ou seja, no estudo da dinamicidade da Natureza. A História Natural seria o estudo descritivo e qualitativo da Natureza, abordado organicamente. Assim, começaria com as disciplinas relacionadas aos organismos minerais e da terra, passando pelas plantas e animais até se chegar ao homem (como um ser natural) (HARRIS, 1870).

\footnotetext{
2 Harris preferiu o termo divisão em vez de classe, muito provavelmente, por influência de Hegel, que na obra Ciência da Lógica, ao discorrer sobre classificação, adotou termos como 'divião geral da lógica', 'divisão do ser' e 'divisão do conceito'. Segundo Ferrer (2009), no que se refere a Hegel, divisão equivale a classificação.
} 
A transição das ciências para as artes úteis seria marcada pela Medicina, que era, segundo Harris, um saber em parte ciência, em parte arte. As Artes Úteis estavam voltadas à aplicação das leis da Natureza, aos seus usos sociais.

Nesse sentido, observa-se que a classe geral Ciência foi desdobrada por Harris partindo de uma perspectiva mais abstrata, de ideias formativas, para chegar a uma perspectiva mais empírica, de produção. Em outras palavras, Harris entendia que para compreender o curso lógico das ciências e, consequentemente, classificá-lo, era necessário partir das formas racionais estruturantes (Filosofia; Teologia), tomar ciência dos organismos sociais (Ciências Políticas e Sociais), descrever quantitativa e qualitativamente as leis e dinâmicas da Natureza (Ciências Naturais) até chegar ao elemento empírico (Artes Úteis).

b) Desdobramentos da Arte (segunda classe geral / segunda divisão geral):

Como o empirismo dos meios de produção já foram aparentemente introduzidos na classe geral anterior, como transição entre as ciências e as artes, Harris (1870) foi mais sucinto ao explanar sobre o desenvolvimento de sua segunda classe geral, a Arte. Seguindo a coerência de começar sempre com os assuntos mais próximos da classe geral, Harris, ao desdobrar os saberes atinentes à Arte, adotou um percurso que iniciava pela abordagem mais generalista, representada pela classe Belas Artes, prosseguindo para a classe que abarcava os meios de "imaginação produtiva", designada amplamente pela Poesia.

Respeitando o princípio norteador para as divisões principais, que definia que a ordenação sequencial devia ser feita com base nos assuntos que realizavam as características da classe geral da maneira mais completa para a menos completa, Harris alocou depois da classe Poesia as classes Fiç̧ão em prosa e Miscelânea literária, esta última composta por obras retóricas e ensaios literários.

c) Desdobramentos da História (terceira classe geral / terceira divisão geral):

A terceira classe geral de Harris, História, foi igualmente desdobrada a partir do princípio de que a divisão de uma classe geral deve iniciar com a abordagem mais externa, ou mais genérica, do conhecimento a ser classificado. Nesse sentido, Harris entendia que Geografia e Viagens configurariam a abordagem mais externa da História, formando a primeira classe desta última. Em seguida viria a classe História Civil, que, segundo o autor, era um tipo normal de História e, por último, a classe Biografia e Correspondência (genealogia e heráldica pertenceriam também a esta classe).

\section{d) Apêndice}

Para complementar suas principais classes, Harris abriu espaço para um quarto conjunto de tipos de documentos, ou seja, o Apêndice. De acordo com o autor, "an appendix is subjoined for certain works or collections of works, which treat of topics belonging to each of the three general divisions" (HARRIS, 1870, p.124). Esta medida complementar demonstra a preocupação prática na organização dos documentos da biblioteca. A Tabela 2 apresenta o esboço do esquema classificatório de Harris. 
Tabela 2: Esquema das classes de Harris.

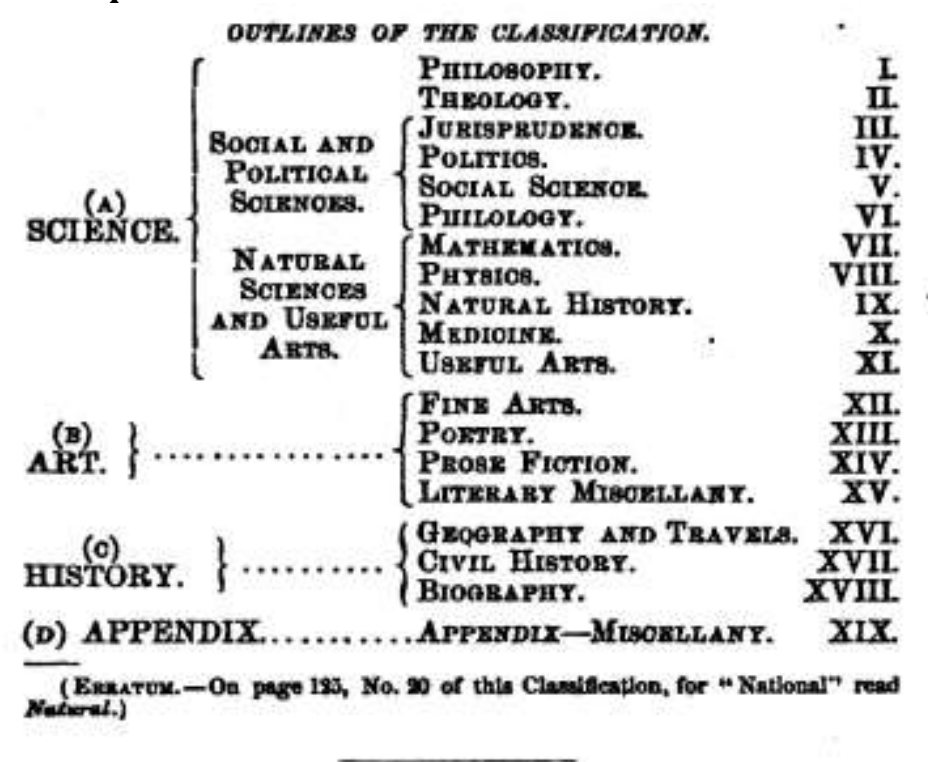

Fonte:Harris (1870)

\subsection{Influências de Bacon e Hegel: um olhar crítico}

Se a influência de Bacon na classificação de Harris foi declarada pelo próprio autor em seu artigo (1870), o mesmo não ocorreu com a influência de Hegel, muito provavelmente, pelo fato de Harris estar completamente imerso no idealismo hegeliano, a ponto de tal influência não ter carecido de declaração explícita.

De Bacon, Harris não herdou somente o princípio de ideia formativa e estruturante, que pretendia organizar o conhecimento de acordo com as faculdades mentais, mas também a crença de que os fenômenos ou as coisas existentes possuíam uma disposição e uma dinamicidade capazes de ser capturadas formalmente. Para Bacon, os fenômenos naturais eram compostos por duas faces:

Por um lado, eles possuem uma certa disposição, conformação ou estrutura (esquematismo latente, na terminologia baconiana). Por outro lado, possuem um aspecto dinâmico, que os faz apresentarem-se em permanente transformação (processo latente). Ambos os aspectos são conexos e têm como princípio a "forma", princípio essencial de individuação e lei que rege a geração, ou produção, e o movimento dos fenômenos (ANDRADE, 1999, p. 16).

A "forma", para Bacon, seria o ponto final do método indutivo, ou seja, a formalização e consolidação do conhecimento decorrente da abordagem empírica, capaz de dar conta tanto da dimensão estática quanto dinâmica dos fenômenos naturais.

Trazendo esta lógica baconiana para a realidade das classificações do conhecimento, observa-se que a formalização das classes gerais de Bacon pode ter sido baseada na abordagem empirista, uma vez que, a partir deste pensamento, o filósofo pode ter justificado que primeiro o homem lembra, depois imagina e produz e, por último, raciocina. Nota-se nesta justificativa que o empirismo característico de Bacon poderia estar manifesto na ideia de que o conhecimento ou a razão seria possível em decorrência da experiência criativa, e este percurso poderia ser capturado pela forma memória-imaginação-razão. A memória, representada pela classe História, encabeçava a estrutura classificatória de Bacon porque, como já afirmou Harris (1870), a abordagem histórica estava mais bem consolidada no 
século XVII do que a abordagem científica, cujos contornos não pareciam ainda tão definidos. A imaginação, representada pela classe Poesia, muito próxima de sua significação etimológica - dar determinação a algo; moldar - parecia dialogar perfeitamente com a ação criativa e inventiva, o que induziria a uma razão, representada, por sua vez, pela Filosofia.

Porém, cabe destacar que se para a ordenação das classes gerais Bacon adotou uma lógica induzida pelo empirismo, no que se refere à ordenação interna das classes Bacon empregou a lógica hierárquica dedutiva, que parte do mais geral para o mais particular. Se Harris concordou com a possibilidade de formalizar a classificação do conhecimento por meio de uma estrutura baseada nas faculdades mentais, e por meio de uma hierarquia interna que se movia do mais geral para o mais particular (presentes tanto em Bacon como em Hegel), certamente ele discordou da ordenação caracteristicamente empírica proposta por Bacon, preferindo o idealismo hegeliano encabeçado pela razão, que na época de Harris, era melhor representado pela classe Ciência, conforme verificado na Tabela 2.

$\mathrm{Na}$ lógica hegeliana, tanto o universal deveria se particularizar até o individual, como o conteúdo individual deveria, por meio da particularidade, generalizar-se até o universal (HEGEL, 2011). Assim, Hegel, ao pensar aspectos de ordenação, guiado por três momentos quantitativos - individual (I), particular (P) e universal (U) - defendia a necessidade de se adotar tanto a lógica dedutiva (do genérico para o específico) quanto a lógica indutiva (do específico para o genérico). Esta relação hierárquica universal-particular-individual ou individual-particularuniversal, repercutiria não somente na classificação de Harris, mas em diversos esquemas classificatórios subsequentes, notadamente nas relações gênero-espécie e todo-parte.

Para lidar com essas relações, Hegel (2011) adotou o processo de "divisão", que Harris (1890) interpretou como processo de "classificação".

Para Harris (1890), "Classification is a synthetic operation in which is expressed the necessary relation of all the determinations of the universal" (p. 394). Para lidar com tais determinações, o filósofo deve procurar soluções para problemas de sua época com base em seus antecessores e em seus contemporâneos. Segundo o filósofo norteamericano,

Just as natural science progress by the accumulation of observation and reflection, so philosiphy, too, progresses by combining the results of human speculation. In science each observer sees nature through the eyes of all preceding observers, and makes of their reflection in classification and explanation. In philosophy each thinker refines on the systems of those who have gone before, and uses contemporary thought to assist his own definitions (HARRIS, 1890, p. 17)

Indiscutivelmente, Hegel foi o antecessor de Harris que mais o influenciou. 0 desafio está em identificar tal influência no que se refere à classificação.

Hegel acreditava que a divisão (classificação) de um conceito era determinada pelo próprio conceito, assim, partia do pressuposto "que a divisão tem de estar conectada ao conceito ou, muito mais, residir nele mesmo [...] o conceito não é indeterminado, mas determinado nele mesmo" (Hegel, 2011, p. 40). A divisão seria para Hegel o juízo do conceito, determinado por ele mesmo. Hegel ilustra esta perspectiva com o seguinte exemplo:

0 caráter de retângulo, acutângulo etc., assim como do equilátero etc., segundo cujas determinações se dividem os triângulos, não reside na determinidade do triângulo mesmo, isto é, no que se costuma chamar de conceito do triângulo. Tampouco, naquilo que vale como o conceito de animal em geral ou de mamífero, de pássaro etc., residem as determinações segundo as quais aquele é 
dividido em mamíferos, pássaros etc. e essas classes em gêneros ulteriores. Tais determinações são extraídas de outros lugares, da intuição empírica; elas se acrescentam do exterior ao assim chamado conceito. No tratamento filosófico do dividir, o conceito deve se mostrar a si mesmo como contendo sua origem (HEGEL, 2011, p. 40).

Essa visão da divisão dos conceitos é pertinentemente explicada por Ferrer (2009), que afirma ser a classificação de Hegel em parte empírica, em parte racional e reveladora de aspectos importantes no nível conceitual. Segundo Ferrer (2009), ao se referir à classificação dos seres, Hegel acreditava ser possível definir um "universo concreto", que seria alcançado por meio de um processo objetivo que, por sua vez, era composto pelo princípio de sociabilidade e de reconhecimento da espécie. A determinação da espécie não seria assim realizada por um observador externo, mas sim pelo próprio organismo vivo. Nessa oportunidade Hegel deixaria clara sua opinião contrária à arbitrariedade e à artificialidade das classificações.

0 vivente classifica-se a si próprio e exibe o conhecimento de sua espécie como comportamento objectivo de pertença e reconhecimento. A classificação não é, por isso um procedimento exterior de um sujeito classificador, mas corresponde a uma realidade objetiva. Contra os denominados "sistemas artificiais", Hegel compreende que a determinação da espécie não é uma simples comparação e pesagem de semelhanças e diferenças, mas que depende de uma realidade objectiva do vivente (FERRER, 2009, p. 39).

Nesse sentido, o sistema de classificação surgiria em decorrência de uma autoclassificação objetiva, pois somente assim seria possível expressar um conhecimento universal. A disposição das espécies empiricamente existentes seria capturada por um esquema racional de conceptualização indissociavelmente ligado à realidade. A espécie seria ao mesmo tempo um elemento universal classificado com os demais indivíduos singulares empíricos e, por outro lado, uma determinação real da natureza. Desse modo, a espécie viva de Hegel passaria a ter um valor ideal e real, seria, ao mesmo tempo, conhecimento e ser (FERRER, 2009).

No idealismo hegeliano, o sistema era tratado como o universal mais geral, e essa totalidade era ao mesmo tempo ideal e real, em que o ideal era determinado pelo próprio relacionamento objetivo de cada momento real, e o momento real recebia um lugar próprio dentro do sistema universal. Nesta perspectiva, pensando na classificação filosófica dos conceitos, Hegel afirmava que uma divisão filosófica não era uma classificação exterior de um assunto disponível, realizada com base em fundamentos de divisão, mas sim o diferenciar imanente do próprio conceito (FERRER, 2009).

Inserido nesta concepção idealista, Harris, como pode ser observado na Tabela 2 exposta mais acima, e na Tabela 3 exposta mais adiante, definiu seu esquema classificatório movido pelo desejo de organizar tematicamente o acervo da biblioteca da escola pública de St. Louis de modo a refletir os assuntos dos livros como eles supostamente se relacionavam no sistema universal do conhecimento. Embora não declarada, a influência idealista de um todo universal, que capturava tanto o ideal racional como o real empírico, esteve presente na definição das classes do sistema de Harris.

Uma das influências hegeliana percebida na classificação de Harris foi já levantada por Olson (2011) ao explanar sobre a associação das três categorias de existência de Hegel com as três classes gerais de Harris: a História associada ao Ser (como aquilo que é imediatamente percebido); a Arte com a Essência (como uma condição de mediação) e; a Ciência com a Ideia (categoria que transcende tanto a 
percepção quanto a mediação). Embora esta associação tenha sido feita por Harris somente no livro de 1890, ao trazer tal configuração para a classificação de 1870, é possível notar que Harris classificou seu universo de assuntos na perspectiva de que a Ciência, ao transcender a percepção e a mediação, tornava-se a classe principal, responsável por dar os arquétipos do saber (HARRIS, 1870), assim como a categoria Ideia era a categoria principal e absoluta no idealismo hegeliano. E aqui reside o motivo fundamental da inversão da ordem baconiana concebida por Harris.

Saberes como Filosofia, Teologia, Ciências Sociais e Ciências Naturais não seriam nem meras mediações nem meras percepções, mas sim saberes responsáveis pelas definições de modelos.

Já as Belas Artes, a Poesia, a Prosa e as obras gerais de Literatura, cumprindo com a função de imaginação criativa e produtiva, enquadravam-se como saberes de mediação (categoria Essência), pertencentes à segunda classe geral - Arte. Geografia $e$ Viagens, História Civil e Biografia, pertencentes à classe geral História, na classificação de Harris assumiam o papel dos saberes responsáveis pelo registro e pela memória, percepção imediata (categoria Ser).

Tabela 3: Classes de Harris.

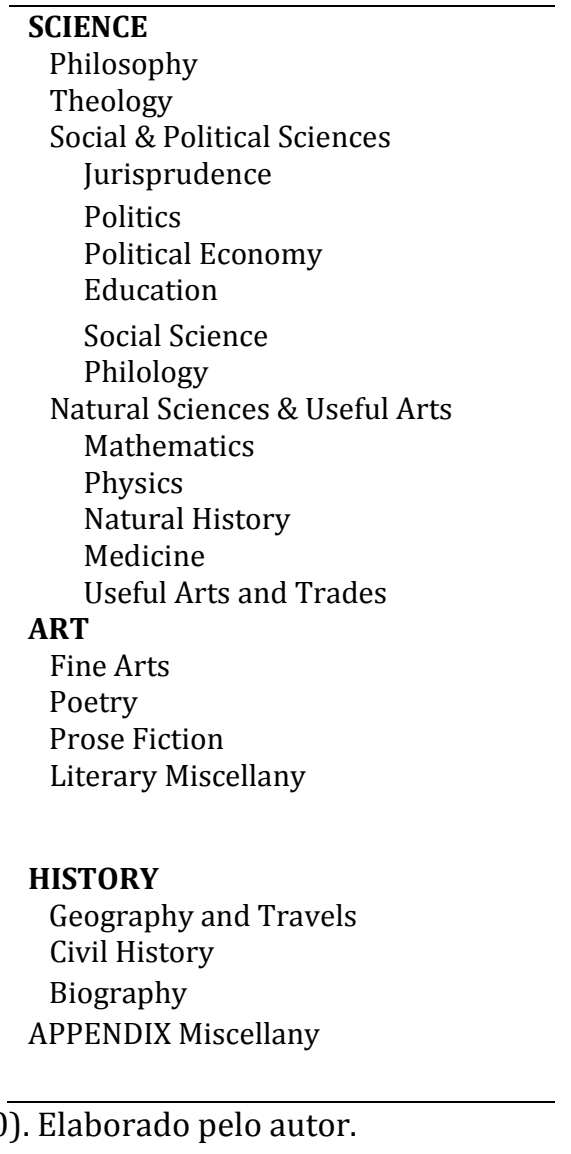

Fonte: Harris (1870). Elaborado pelo autor.

Observa-se na Tabela 3, que a primeira classe geral, Ciência, foi mais bem desdobrada por Harris que as outras duas, Arte e História. Assim como Hegel deu primazia à categoria Ideia, que transcendia a imediatez da percepção e a ilusão da mediação, Harris deu especial atenção à classe Ciência, por ser ela, segundo o filósofo americano, definidora de modelos e formas, esquematizadora de possibilidades de conhecer, criadora de métodos. A formação filosófica de Harris e o hegelianismo latente em seu pensamento, possivelmente o impossibilitou de tomar outro caminho senão atribuir à Ciência (associada à Ideia de Hegel), protagonismo fundamental na classificação do conhecimento, delegando à Arte e à História as 
funções de mediar e registrar o conhecimento. Assim, percebe-se uma classificação orientada pelo idealismo de Hegel, que teve como ponto de partida a perspectiva histórica e empirista de Bacon.

Em outras palavras, ao apoiar-se nas ideias formativas de Bacon e de Hegel, a classificação de Harris, construída na crença de ser possível definir um universal como um todo, composto pelo real e pelo ideal, formaliza uma visão idealista do universo do conhecimento. Desse modo, a dialética empirista de Bacon e a dialética idealista de Hegel estão impressas nas classificações de biblioteca por meio da classificação de livros de William Torrey Harris, que pode ser entendida como um elo forte entre a Filosofia e a Biblioteconomia no século XIX.

\section{CONCLUSÕES}

Com a análise apresentada neste ensaio, que procurou descrever e comparar criticamente a classificação de livros de Harris com as perspectivas classificatórias de Bacon e Hegel, foi possível abordar Harris como o responsável por introduzir ao universo das classificações de biblioteca influências filosóficas que moldariam os estudos das classificações bibliográficas, fortemente influenciados pela lógica hierárquica e idealista.

A afirmação de que a classificação de Harris, bem como sua influência de Bacon e Hegel, repercutiriam nas principais classificações bibliográficas dos séculos XIX e XX, pontuando sua importância na história das classificações, a literatura já havia se encarregado de fazer. 0 que não parecia ainda tão claro, e há que se ressaltar que este ensaio não teve de forma nenhuma a pretensão de encerrar o assunto, é como Harris se apropriou das ideias de Bacon e de Hegel para formalizar sua classificação de livros.

De Bacon, Harris se apropriou da ideia formativa do conhecimento baseada nas faculdades mentais do homem e da hierarquia dedutiva que ordenava internamente os assuntos do mais geral para o mais específico. Há que se dizer que Bacon, assim como Hegel, também acreditava ser possível capturar uma forma que definisse tanto a estrutura quanto a dinamicidade do conhecimento.

De Hegel, Harris herdou o foco centrado na Ideia, na razão modelada pela Ciência, o que tornou sua classificação logicamente idealista. Este foco centrado nas ciências fez com que Harris adotasse as classes baconiana de maneira invertida, dando maior relevância àquilo que no século XIX e na ótica hegeliana seria principal - a razão.

O universalismo defendido tanto por Bacon, por meio do esquematismo latente e do processo latente, quanto por Hegel, por meio da idealização de uma conceptualização racional combinada com uma realidade empírica, unia ambos os filósofos na crença de que a classificação teria algo de natural e não artificial, algo capaz de refletir ou representar a realidade como tal e de maneira racional. Essa visão contrária à artificialidade e à arbitrariedade influenciaria Harris a ponto de desenvolver uma classificação de livros na esperança de conduzir leitores e estudantes que desejassem um olhar abrangente sobre a totalidade da inteligência humana materializada nos livros.

Esta preocupação de ordem prática, alinhada a uma filosofia idealista, fez Harris introduzir na organização do conhecimento praticada pela Biblioteconomia, notadamente nas classificações bibliográficas, parte do pensamento de Bacon e de Hegel.

\section{REFERÊNCIAS}

ANDRADE, J. A. Reis. de. Bacon: vida e obra. São Paulo: Nova Cultural, 1999. 
BARBOSA, A. P. Teoria e prática dos sistemas de classificação bibliográfica. Rio de Janeiro: Instituto Brasileiro de Bibliografia e Documentação, 1969. 441 p. (Obras Didáticas; 1).

COMAROMI, John Phillip. The eighteen editions of the Dewey Decimal Classification. Albany, NY: Forest Press Division, Lake Placid Education Foundation, 1976.

FERRER, D. Espécies, classificação e evolução em Hegel. Revista Eletrônica Estudos Hegelianos, ano 6, n 11, jul-dez/2009, pp. 32-56.

FOSKETT, A.C. A abordagem temática da informação. Tradução de Antônio Agenor Briquet de Lemos. São Paulo: Polígono; Brasília: Ed.UnB, 1973.

HARRIS, W. T. Book classification. Speculative Philosophy, St. Louis, v. 4, p. 114-129, 1870.

HARRIS, W. T. Hegel's logic: a book on the genesis of the categories of the mind: A critical exposition. Chicago: S.C. Griggs, 1890.

HEGEL, G. W. F. Ciência da Lógica: excertos. Tradução de Marco Aurélio Werle. São Paulo: Barcarolla, 2011.

La MONTAGNE, L. E. American library classification: with special reference to the Library of Congress. Handen: The Shoe String Press, 1961.

LEIDECKER, K. F. Yankee teacher: the life of William Torrey Harris. New York: The Philosophical Library, 1946. Reimpresso por: New York: Kraus Reprint, 1971.

MILLS, J. A morden outline of library classification. London, Chapman and Hall, 1960.

OLSON, H. A. A potência do não percebido: Hegel, Dewey e seu lugar na corrente principal do pensamento classificatório. Tradução de Márcia Regina Silva. InCID: Revista de Ciência da Informação e Documentação, v. 2, n. 1, p. 3-15, jan./jun. 2011.

PIEDADE, M. A. R. Introdução à teoria da classificação. 2. ed. Rio de Janeiro: Interciência, 1983.

SALES, R. de. A organização da informação de Julius Kaiser: o nascimento do método analítico-sintético. Saarbrücken, Alemanha: Novas Edições Acadêmicas, 2014.

SCHNEIDER, G. Theory and history of bibliograph. New York: Columbia University, 1934. (Columbia University Studies in Library Service, n.1).

WIEGAND, W. A. Irrepressible reformer: a biography of Melvil Dewey. Chicago: American Library Association, 1996.

WIEGAND, W. A.. The "Amherst Method": the origins of the Dewey Decimal Classification scheme. Libraries \& Culture, Austin, v. 33, 175-194, 1998. 